\title{
BMJ Open Prehospital and in-hospital delays to care and associated factors in patients with STEMI: an observational study in 101 non-PCI hospitals in China
}

\author{
Lin Feng, ${ }^{1,2,3}$ Min Li, ${ }^{4}$ Wuxiang Xie, ${ }^{2}$ Aihua Zhang, ${ }^{3}$ Licheng Lei, ${ }^{5}$ Xian Li, ${ }^{3}$ R Gao, ${ }^{6}$ \\ Yangfeng $\mathrm{Wu}^{2,3,7}$
}

To cite: Feng L, Li M, Xie W, et al. Prehospital and inhospital delays to care and associated factors in patients with STEMI: an observational study in 101 non-PCl hospitals in China. BMJ Open 2019;9:e031918. doi:10.1136/ bmjopen-2019-031918

- Prepublication history and additional material for this paper are available online. To view these files, please visit the journal online (http://dx.doi org/10.1136/bmjopen-2019031918).

Received 25 May 2019 Revised 23 September 2019 Accepted 18 0ctober 2019

Check for updates

(C) Author(s) (or their employer(s)) 2019. Re-use permitted under CC BY-NC. No commercial re-use. See rights and permissions. Published by BMJ.

For numbered affiliations see end of article.

Correspondence to Dr Yangfeng Wu; wuyf@bjmu.edu.cn

\section{ABSTRACT}

Objectives To describe the prehospital and in-hospital delays to care and factors associated with the delays among patients with ST-segment elevation myocardial infarction (STEMI) in non-percutaneous coronary intervention (PCl) hospitals in China.

Design, setting and participants We analysed data from a large registry-based quality of care improvement trial conducted from 2011 to 2014 among 101 non-PCl hospitals in China. A total of 7312 patients with STEMI were included. Prehospital delay was defined as time from symptom onset to hospital arrival $>120 \mathrm{~min}$, first ECG delay as time from arrival to first ECG $>10 \mathrm{~min}$, thrombolytic therapy delay as time from first ECG to thrombolytic therapy $>10$ min and in-hospital delay as time from arrival to thrombolytic therapy $>30$ min. Logistic regressions with generalised estimating equations were preformed to identify the factors associated with each delay.

Results The rates of prehospital delay, first ECG delay, thrombolytic therapy delay and in-hospital delay were $67.1 \%, 31.4 \%, 85.8 \%$ and $67.8 \%$, respectively. Patients who were female, older than 65 years old, illiterate, farmers, onset during late night and forenoon, had heart rate $\geq 100$ beats $/ \mathrm{m}$ at admission were more likely and patients who had history of myocardial infarction, hypertension or SBP $<90 \mathrm{~mm} \mathrm{Hg}$ at admission were less likely to have prehospital delay. First ECG delay was more likely to take place in patients arriving on regular hours. Thrombolytic therapy delay rate was lower in patients who had prehospital delay or first ECG delay but higher in those with heart rate $\geq 100$ beats/m at admission. In-hospital delay rate was lower in patients with a history of dyslipidaemia and those who arrived during regular hours. Conclusion Chinese patients with STEMI in low medical resource areas suffered severe prehospital and in-hospital delays to care. Future efforts should be made to improve the prehospital delay among vulnerable populations with low socioeconomic status.

Trial registration number NCT01398228; Post-results.

\section{INTRODUCTION}

Total ischaemic time (time from symptom onset to thrombolytic therapy) is an important indicator to the prognosis of patients with ST-segment elevation myocardial infarction (STEMI). ${ }^{2}$ In general, the total ischaemic
Strengths and limitations of this study

- This study provides insights into the prehospital and in-hospital delays to care among patients with STEMI in low medical resource areas with a large sample from 101 non-percutaneous coronary intervention hospitals across China.

- The study used prospective data to investigate influencing factors of first ECG delay and thrombolytic therapy delay in patients with STEMI.

- We could not exclude the influence of patient's recall bias for symptom onset time. However, data were collected during patient's admission within a very narrow time after STEMI onset.

- Survivor bias might exist as patients who were dead on arrival or within 10 min of hospital arrival were excluded.

- We did not collect the onset of symptoms and hence could hardly study on the possible associations between the symptoms and the delays to care.

time comprises three consecutive segments. The time from symptoms onset to the hospital arrival represents the time patients spend to respond to the disease onset and seeking medical care. The time from hospital arrival to having the first electrocardiograph (ECG) in hospital represents the time for hospital staff's responses to the patient's medical presentations, and with the first ECG done in time the working diagnosis of STEMI could be made and appropriate treatments could be initiated. The time from diagnosis to treatment represents doctors' responses to the diagnosis of disease. Delay in each segment can lead to longer ischaemic time, which has been found to be associated with higher short-term as well as medium-term to longterm mortality in previous studies. ${ }^{3-5}$

Meanwhile, recent studies indicate that time delays to care among patients with STEMI exist universally, showing a worse situation in low-income and middle-income 
countries than in high-income countries, ${ }^{6-9}$ such as $28.7 \%$ of patients with acute coronary syndrome (ACS) in Germany but two-thirds of patients with STEMI in Brazil suffered first ECG delay. ${ }^{78}$ The delays to care in patients with STEMI remain great challenges to be overcome across all countries.

Till the present times, quite a few studies have tried to better understand the reasons behind these delays and showed that sociodemographic factors (female gender, older age, low educational level), medical histories (diabetes, myocardial infarction), ambiguous heart symptoms, use of private transport were related to longer delay in at least one of the four kinds of time delays. ${ }^{710-12}$ Based on these findings, some national or regional programmes have been initiated to reduce the delays by targeting at controlling these factors, through educational campaigns, implementation of prehospital ECG, establishing regional collaborative networks, and so on, and these actions have turned out to be effective. ${ }^{13-16}$

However, almost all of those studies focused on prehospital delay and the patients who had access to onsite primary percutaneous coronary intervention (PCI) procedures. Those evidences have limited value for nonPCI hospitals in remote areas where fibrinolysis is the main reperfusion option for patients with STEMI. Therefore, the aims of the present study are (A) To describe the time delays among patients with STEMI in non-PCI hospitals in China. (B) To identify factors associated to these delays. (C) To make suggestions for reducing these delays and improving care of patients with STEMI in similar settings in China and other countries.

\section{METHODS}

\section{Study population}

We used data of the patients with STEMI from a very large registry-based quality of care improvement trial, the third phase of the Clinical Pathways for Acute Coronary Syndromes (CPACS-3) in China. ${ }^{17}$ In brief, patients in the CPACS-3 Trial were recruited consecutively from 101 regional hospitals without the capacity to perform onsite PCI between October 2011 and November 2014. All patients were over 18 years old and with a final diagnosis of ACS at discharge or death. The patients who were dead on arrival or within $10 \mathrm{~min}$ after hospital arrival were excluded. For the present study, we further excluded patients whose data of time at either symptoms onset, hospital arrival, having the first ECG or receiving thrombolytic therapy were missing. From a total 10294 patients with STEMI recruited in the CPACS-3 Trial, we had 7312 patients analysed with complete data. The study flow diagram is shown in figure 1 .

All participating patients provided written informed consent.

\section{Data collection and verification}

A trained hospital staff member, who was not involved in the management of patients with ACS, was responsible
10,294 consecutive STEMI patients from Oct. 2011 to Nov. 2014

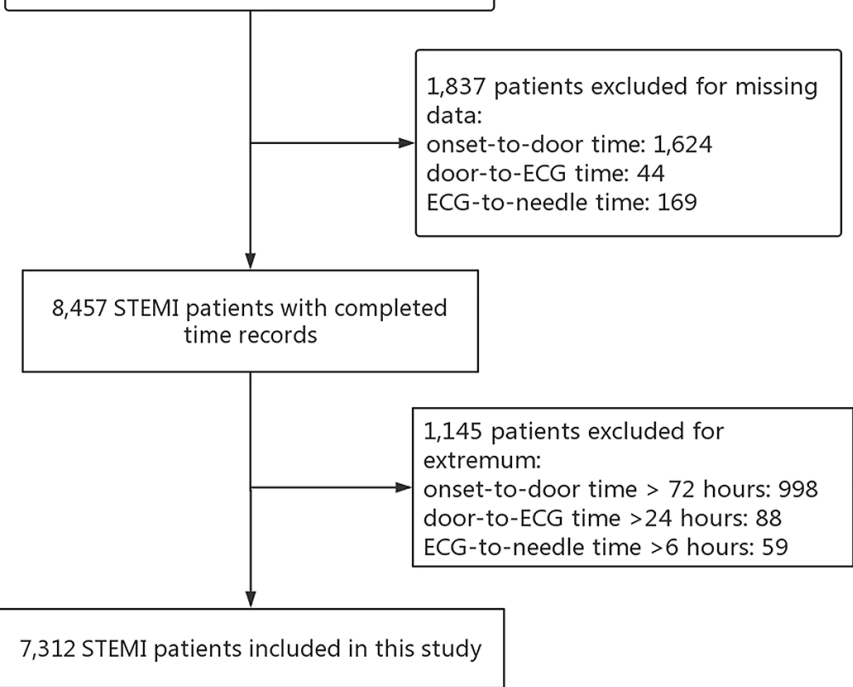

Figure 1 Study flow diagram of included patients. STEMI, ST segment elevation myocardial infarction.

for collecting and entering data into a dedicated webbased data management system. Data of each patient were collected from medical records. The data included sociodemographic information, vital signs relating to the presenting ACS, medical history, ECG findings, biomarker findings, investigations performed, treatments administered prior to admission, during hospitalisation, and at death or hospital discharge, final diagnosis and discharge status, major in-hospital clinical events, personal insurance status and the total cost of hospitalisation. Data quality was maintained through independent centrally managed in-person and on-line study monitoring activities.

\section{Definitions and outcomes}

Symptom onset time was defined as when the patient first noted ischaemic symptoms lasting $\geq 10 \mathrm{~min} ;{ }^{18}$ hospital arrival time was defined as when the patient arrived at emergency or outpatient department for help. Prehospital delay was defined as the time from symptoms onset to hospital arrival (symptoms onset-to-hospital arrival time) $>120$ min. $^{11} 1920$ Most of hospitals without PCI facility in China are located in rural areas, where prehospital emergency system is either not existing or is pretty weak. The ambulances serve only as transportation vehicles but with no ECG equipment or the results are not able to be transmitted back to the hospital. Thrombolytic therapy remains an in-hospital practice throughout the whole country up to now. Thus, the first ECG delay was defined as the time from patient's arrival at hospital to the time the patient had the first ECG done (hospital arrival-to-ECG time) $>10 \mathrm{~min}^{21}{ }^{22}$ The working diagnosis of STEMI should had been made by then. The thrombolytic therapy delay was defined as the time when patient had the first ECG done to the time the thrombolytic therapy was initiated (ECG-to-thrombolytic therapy time) 
$>10$ min. ${ }^{21}$ In-hospital delay was defined as the time from hospital arrival to the time the thrombolytic therapy was initiated (hospital arrival-to-thrombolytic therapy time) $>30$ min. $^{23}$

\section{Statistical analysis}

The baseline characteristics of our study patients were described as percentages for categorical variables and means with SDs for continuous variables. Wilcoxon tests were adopted for comparison of the time durations and Pearson $\chi^{2}$ tests for the comparison of proportions between thrombolytic therapy patients and non-thrombolytic therapy patients. Logistic regressions with generalised estimating equations were used to explore the associates of the time delays (prehospital delay, first ECG delay, thrombolytic therapy delay, in-hospital delay), with an exchangeable correlation structure to account for clustering effect within hospitals. ${ }^{24}$ Covariates in multivariate analyses were selected based on clinical and sociodemographic interests and the results of univariate analyses. Missing data of covariates (all categorical variables) were handled as separated groups in multivariate analyses. We used SAS V.9.4 (SAS Institute, Cary, North Carolina, USA) to perform data analyses. The significant level $\alpha$ was set at 0.05 .

\section{Patient and public involvement}

No patients but government officers who were responsible for hospital management were involved in the CPACS-3 study design.

\section{RESULTS}

The characteristics of the included patients are summarised in table 1 . Their ages range from 19 years to 102 years and the mean age is 63.4 years. Most patients were male $(71.2 \%)$, more than half were farmers $(67.2 \%)$ and almost all were covered by medical insurance $(94.1 \%)$. Almost a third of them were illiterate. The vital signs, cardiovascular risk factors and history of cardiovascular diseases are shown in table 1.

\section{The delays to care}

For all patients with STEMI, 67\% had experienced prehospital delay and $31 \%$ experienced first ECG delay. The patients receiving thrombolytic therapy had significantly less prehospital and first ECG delays, compared with patients not receiving therapy. Among the patients receiving thrombolytic therapy, $86 \%$ initiated treatment after 10 min of the first ECG and $68 \%$ after 30 min of arrival at hospital.

Whether patients received thrombolytic therapy or not, symptoms onset-to-arrival time was the dominant time segment, accounting for two-thirds of the total ischaemic time among those who received thrombolytic therapy. Patients who did not receive thrombolytic therapy suffered more than twice the symptoms onset-to-arrival
Table 1 Characteristics of included patients

\begin{tabular}{|c|c|}
\hline Characteristics & $\begin{array}{l}\text { All patients with STEMI } \\
(\mathrm{n}=7312)^{*}\end{array}$ \\
\hline Male, no. (\%) & 5205 (71.2) \\
\hline Age, mean (SD), year & $63.37(12.42)$ \\
\hline Farmer, no. (\%) & $4715(67.2)(n=7013)$ \\
\hline Illiteracy, no. (\%) & $1604(27.7)(n=5799)$ \\
\hline Medical insurance, no. (\%) & $5140(94.1)(n=5462)$ \\
\hline \multicolumn{2}{|l|}{ Cardiovascular risk factors } \\
\hline Current smoking, no. (\%) & $2488(34.7)(n=7170)$ \\
\hline Hypertension, no. (\%) & $4588(62.8)$ \\
\hline Dyslipidaemia, no. (\%) & 279 (3.8) \\
\hline Diabetes, no. (\%) & $851(11.6)$ \\
\hline \multicolumn{2}{|l|}{ Cardiovascular disease history } \\
\hline Myocardial infarction, no. (\%) & $460(6.3)$ \\
\hline Angina, no. (\%) & $805(11.0)$ \\
\hline Stroke, no. (\%) & $635(8.7)$ \\
\hline TIA, no. (\%) & $111(1.5)$ \\
\hline Heart failure, no. (\%) & $160(2.2)$ \\
\hline \multicolumn{2}{|l|}{ Symptom onset time } \\
\hline 00:00-05:59, no. (\%) & $1315(18.0)$ \\
\hline 06:00-11:59, no. (\%) & $2681(36.7)$ \\
\hline 12:00-17:59, no. (\%) & 1896 (25.9) \\
\hline 18:00-23:59, no. (\%) & $1420(19.4)$ \\
\hline \multicolumn{2}{|l|}{ Vital signs at admission } \\
\hline SBP <90 mm Hg, no. (\%) & $407(5.6)(n=7252)$ \\
\hline $\begin{array}{l}\text { Heart rates } \geq 100 \text { beats/min, no. } \\
(\%)\end{array}$ & $832(11.6)(n=7192)$ \\
\hline
\end{tabular}

*Total numbers are shown for variables for which data were not completely reported.

SBP, systolic blood pressure; STEMI, ST segment elevation myocardial infarction; TIA, transient ischaemic attack.

time as their counterparts who received thrombolytic therapy (See table 2).

\section{Factors associated with the delays}

A number of patient-level factors were associated with prehospital delay. The patients who were female, order than 65 years, illiterate, farmers, symptom onset during 00:00-05:59 and 06:00-11:59, with a faster heart rate were more likely to experience prehospital delay. While, patients who had a history of myocardial infarction or hypertension, with a cardiac shock at presentation were less likely to experience prehospital delay (table 3 ).

Few patient-level factors were found to be associated with first ECG delay, thrombolytic therapy delay and in-hospital delay. Only patients who arrived at regular hours independently associated with higher first ECG delay rate. The first ECG delay decreased during the study period (table 3 ). 
Table 2 Time duration and delay in different segments from onset to care among patients with STEMI (min)

\begin{tabular}{|c|c|c|c|c|}
\hline & $\begin{array}{l}\text { All patients with } \\
\text { STEMI }\end{array}$ & $\begin{array}{l}\text { Thrombolytic } \\
\text { therapy patients }\end{array}$ & $\begin{array}{l}\text { Non-thrombolytic } \\
\text { therapy patients }\end{array}$ & P value* \\
\hline \multicolumn{5}{|l|}{ Symptoms onset-to-arrival time } \\
\hline Delay, \% (no. of cases/total number) & $67.1(4903 / 7312)$ & $54.6(1669 / 3057)$ & $76.0(3234 / 4255)$ & $<0.01$ \\
\hline \multicolumn{5}{|l|}{ Arrival-to-ECG time } \\
\hline \multicolumn{5}{|l|}{ ECG-to-thrombolytic therapy time } \\
\hline Time duration, median (IQR) & - & $38(20-65)$ & - & - \\
\hline Delay, \% (no. of cases/total number) & - & $85.8(2623 / 3057)$ & - & - \\
\hline \multicolumn{5}{|l|}{ Arrival-to-thrombolytic therapy time } \\
\hline Time duration, median (IQR) & $260(145-710) \dagger$ & $210(135-320)$ & 395 (157-1419)‡ & - \\
\hline
\end{tabular}

${ }^{*}$ Comparison between thrombolytic therapy patients and non-thrombolytic therapy patients.

†Representing symptoms onset-to-thrombolytic therapy time among those who received thrombolytic therapy but symptoms onset-to-ECG time among those who did not receive thrombolytic therapy.

$\ddagger$ Representing onset-to-ECG time.

STEMI, ST-segment elevation myocardial infarction.

Thrombolytic therapy delay was less likely to take place among patients who experienced prehospital delay or first ECG delay. Patients who presented with faster heart rate were more likely to experience a delay in thrombolytic therapy (table 3).

Patients arriving at regular hours and with history of dyslipidaemia were less likely to have in-hospital delay (table 3).

\section{Association of receiving thrombolytic therapy with prehospital delay and first ECG delay}

Patients who suffered prehospital delay or first ECG delay were less likely to receive thrombolytic therapy at the hospital. Even further adjusting for potential confounders, prehospital delay and first ECG delay separately linked to $32 \%$ and $28 \%$ reductions of receiving thrombolytic therapy among our patients (table 4).

\section{DISCUSSION}

\section{Main results}

In the present study, we found that two-thirds of patients with STEMI in non-PCI hospitals in China had prehospital delay after disease onset while seeking medical care; and about a third of them had their first ECG delayed after they arrived at hospitals, according to the criteria from European Society of Cardiology (ESC) and American College of Cariology (ACC)/American Heart Association (AHA) guidelines or previous research. ${ }^{11} 1920$ Among patients who received thrombolytic therapy, as high as $86 \%$ of them had treatment delayed according to the new criteria of ESC (time from ECG to thrombolytic therapy $>10 \mathrm{~min})^{21}$ and $68 \%$ had treatment delayed according to the old criteria, ${ }^{23}$ that is, after $30 \mathrm{~min}$ of hospital arrival.

Compared with patients with STEMI from large medical centres in metropolitan areas of China ${ }^{11}$ and other developed countries, ${ }^{12} 25$ where the median symptoms onset-to-arrival time was about 113-150 $\mathrm{min}$, the median time found in our study was much longer, about $210 \mathrm{~min}$. But our results were similar to those reported in the Middle East ${ }^{9}$ and shorter than those in India. ${ }^{26}$ The first ECG delay in our study was much better than that in Brazil $(67 \%)^{7}$ and India $(55 \%)^{6}$ but worse than that in developed countries like Japan $(18.4 \%)^{27}$ and Germany $(28.7 \%) .{ }^{8}$ As previous studies including ours have demonstrated significant association of ischaemic time with short-term and long-term mortality among patients with STEMI, our findings in this study highlighted the urgent need to reduce delays to care for patients with STEMI in similar settings in China and other developing countries.

Our further analyses showed that prehospital and first ECG delays were significantly associated with the risk of not receiving thrombolytic therapy. In fact, only $43 \%$ of our study patients received thrombolytic therapy. Since these patients admitted to non-PCI hospitals of China often lived far away from large tertiary medical centres equipped with PCI facilities, thrombolytic therapy was the only revascularisation treatment they could have in the first line. Reducing the prehospital and first ECG delays should have great potential to permit more patients with thrombolytic therapy, which in turn will save many 
Table 3 Multivariate analyses of factors associated with prehospital delay, first ECG delay, thrombolytic therapy delay and in-hospital delay, using logistic regression with generalised estimating equations

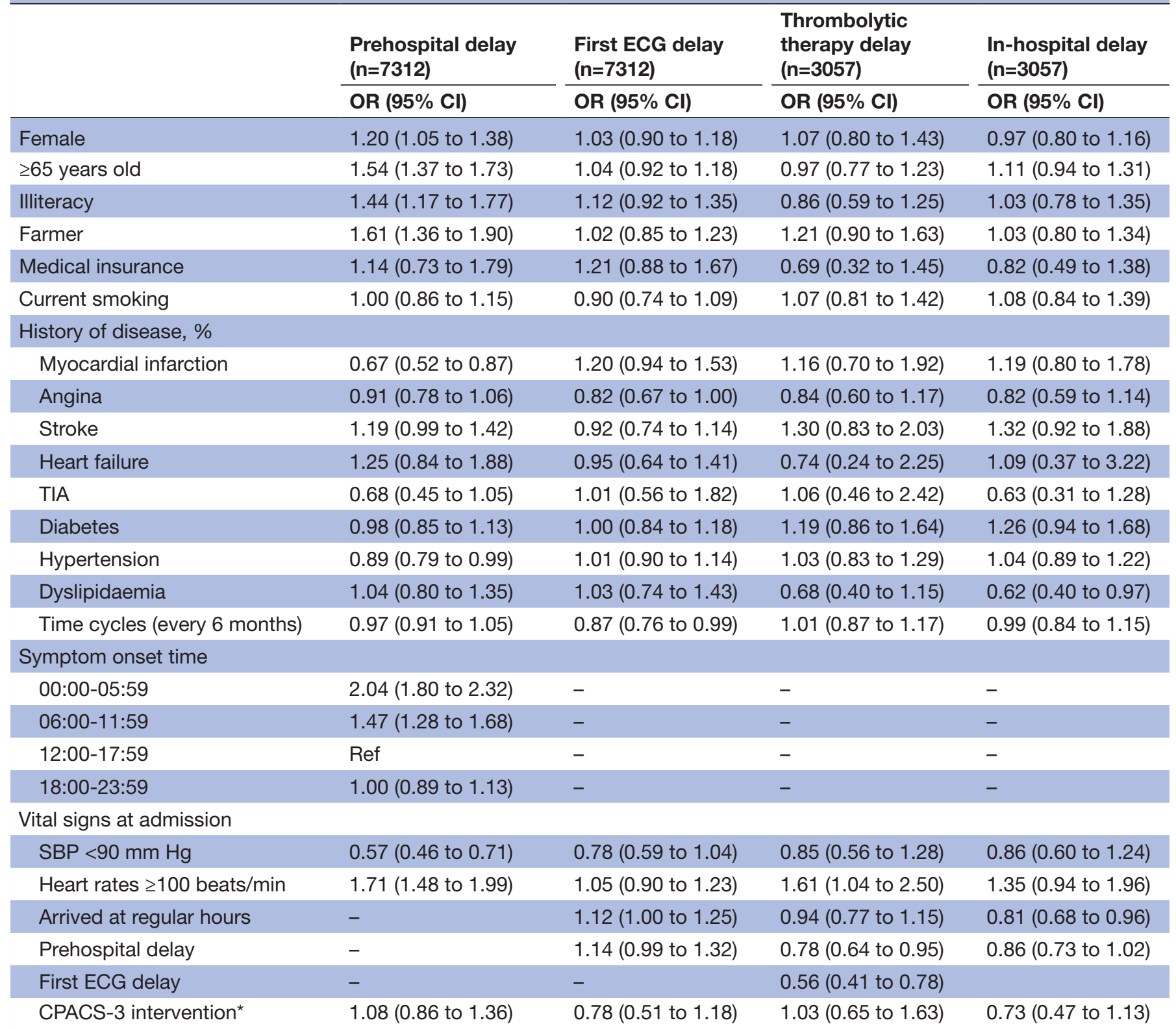

The results of univariate analyses of four kinds of delays are shown in online supplementary table 1.

*The intervention of the third phase of the Clinical Pathways for Acute Coronary Syndromes Study.

CPACS-3, Third phase of the Clinical Pathways for Acute Coronary Syndrome; SBP, systolic blood pressure; TIA, transient ischaemic attack.

more lives in these remote areas. In our study, half of the patients not receiving thrombolytic therapy arrived at the hospital beyond 6 hours after their disease onset and hence lost the best opportunity to receive treatment. If the median time could be reduced to 3 hours, probably most of these patients would still have a chance for thrombolytic therapy.

The study on the factors associated with the delays to care could help find solutions to reduce delays. Like previous studies, the symptoms onset-to-door time took the most part of the total ischaemic time, and we should pay more attention towards reducing prehospital delay. In our study, patients who were older than 75 years, illiterate and farmers were found more likely to have prehospital delay. This implies that efforts should be made to improve medical access for vulnerable patients with low socioeconomic status.

A recent study among Indian patients with STEMI supporting our findings found that the difficulty in arranging for money was an important factor leading to prehospital delay. ${ }^{6}$ Furthermore, elderly and illiterate patients might misinterpret the symptoms of STEMI as symptoms of ageing, aggravating their prehospital delays. ${ }^{20}$

Our findings that women were more likely to have prehospital delays among patients with STEMI have been 
Table 4 Association of receiving thrombolytic therapy with prehospital delay and first ECG delay

Thrombolytic therapy rate (\%)

(no. of cases/total number)

Crude $\mathrm{RR}^{\star}(95 \% \mathrm{Cl})$

Adjusted RR† (95\% Cl)

\begin{tabular}{|c|c|c|c|}
\hline \multicolumn{4}{|c|}{ Prehospital delay } \\
\hline Yes & $34.0(1669 / 4903)$ & 0.62 (0.58 to 0.67 ) & 0.68 (0.64 to 0.73$)$ \\
\hline No & $57.6(1388 / 2409)$ & & \\
\hline Yes & 31.4 (722/2299) & 0.71 (0.66 to 0.76$)$ & $0.72(0.66$ to 0.78$)$ \\
\hline No & $46.6(2335 / 5013)$ & & \\
\hline
\end{tabular}

${ }^{*}$ Crude RR calculated from logistic regression with the generalised estimating equations (GEE) model only included prehospital delay and first ECG delay.

†Further adjusted for sex, age, education level, occupation, medical insurance, current smoking, histories of myocardial infarction, angina, stroke, heart failure, transient ischaemic attack, diabetes, hypertension, dyslipidaemia, time cycles (every 6 months), vital signs at admission, arrived at regular hours, third phase of the Clinical Pathways for Acute Coronary Syndrome (CPACS-3) intervention. $\mathrm{RR}$, risk ratio.

reported in previous studies. ${ }^{9} 11202829$ Possible explanations include women suffering more atypical symptoms, ${ }^{30}$ the women-discriminating culture and lower socioeconomic status, ${ }^{32}$ more sympathy that prevents women from troubling anyone ${ }^{33}$ and so on.

Patients with a history of myocardial infarction, hypertension or presenting with shock at admission were found less likely to have prehospital delay. We believe this is because these patients had more knowledge of myocardial infarction and realised the importance of in-time medical rescue. We believe that patients who presented with shock at admission were found less likely to have prehospital delay due to the severity of the symptoms, which alarmed the patient, family members or a companion, and that helped access to medical care in time. In contrast, we believe that patients who presented with tachycardia at admission were more likely to have prehospital delay probably because of an inverse causal relationship, that is, the tachycardia was a result of prehospital delay.

Similar to previous studies, ${ }^{6} 1112$ we also found patients who suffered prehospital delay had their symptom onset mostly during 00:00 to 05:59. Most people are in sleep during this time, and most patients would not want to bother others at this time if they believed the disease was not severe. Those patients might be prone to going to hospital the next day, avoiding troublesome visits late at night. The phenomenon might be exaggerated by the fact that the most of our study patients were living in rural areas. The barriers for patients living in rural areas seeking medical service include long distance, poor transport facilities and cost concerns. The evidence that patients who had shorter symptoms onset-to-door time had less stroke or heart failure history supported this explanation to some extent.

Because the first ECG delay reflects more medical staff's rather than patients' responses to the disease, no patient side factor was found associated with the first ECG delay in our study. But first ECG delay was found more likely to take place in patients arriving during regular hours. The same results were also found among patients with non ST-segment elavation -ACS in the Can Papid Risk Stratification of Unstable Angina Patients Supress Advers Outcomes with Early Implementation of the ACC/AHA Guidelines (CRUSADE) Quality Improvement Initiative Study. ${ }^{34}$ Although the reasons are still unknown, this relationship may reflect the competition for medical resources by routine clinical patients who rush to hospitals for care. In China, taking an appointment for care is not a common practice.

The recent Strategic Reperfusion Early After Myocardial Infarction (STREAM) Trial demonstrated that thrombolytic therapy (median time from randomisation to bolus recorded was $9 \mathrm{~min}$ ) was as effective as primary PCI beyond 1 hour among patients with STEMI who presented within 3 hours after symptom onset. ${ }^{35}$ Based on the results from the STREAM Trial, the European Society of Cardiology recommended the time from STEMI diagnosis to the start of fibrinolysis to be within 10 min. $^{21}$ According to the new ESC guidelines, only $14 \%$ of patients who received fibrinolysis achieved the 10 min target in our study. Even using the old criteria (in-hospital time $>30 \mathrm{~min}$ ), only $32 \%$ of patients received thrombolytic therapy without delay. We consider this new ESC target time may be ideal but quite unrealistic in rural China now, considering there are many barriers that prevent initiating thrombolytic therapy in such a short time. Particularly, the new type of fibrinolytic agent (tenecteplase), used in the STREAM Trial, is not available in China yet. Hopefully, the ECG-to- thrombolytic therapy time can be shortened as the recombinant human TNK tissue-type plasminogen activator has been approved by China FDA recently, which is applied in the bolus at once and is easy to administer. Meanwhile, due to the possible severe bleeding, the informed patient consent often takes a long time, particularly when the doctor-patient relationship is not good and the medical insurance cannot cover the entire costs.

One of the interesting findings from our study was that among patients receiving thrombolytic therapy, treatment delay was lower in patients who had prehospital 
delay or first ECG delay, reflecting the medical team's 'time catch-up' effort after the patient had a confirmed STEMI diagnosis by ECG examination. Physicians were apt to react more rapidly to make up previous delays, as the effects of the treatment are time-dependent. Nevertheless, we should understand that the physicians' 'catch-up effect' only had limited value for shortening total ischaemic time (see online supplementary tables 2-4), as the major segment was the symptoms onset-tohospital arrival time. More emphases should be put onto reducing prehospital delay.

Our analysis of factors associated with in-hospital delay showed that arrival during regular hours was negatively associated with the risk of in-hospital delay. We believe the results indicate that physicians at regular hours have better capability to 'catch up' the preceding delays once the diagnosis of STEMI has been made.

Another finding was that even with no access to PCI, only half of the eligible patients $(51 \%)$ received thrombolytic therapy. A previous study also reported low thrombolytic therapy rate $(56.1 \%, 2011)$ among eligible patients with STEMI in non-PCI centres in China. ${ }^{36}$ This implies there were other hurdles for patients receiving thrombolytic treatment besides prehospital delay. The possible explanations include doctors' concerns/ worries on patient safety/adverse events, inadequate or no healthcare insurance to cover the cost and the waiting time for the direct family members to agree and sign the informed consent for initiating thrombolytic therapy.

\section{Strengths and limitations}

The strengths of our study include: (1) A large sample from non-PCI hospitals across China. The results could be extended to other places in China and the world with the similar settings. (2) The data were collected prospectively, under strict supervision by an experienced project management team and a steering committee composed of international expertise in cardiology, epidemiology and biostatistics.

The present study also has several limitations. First, we could not exclude the influence of patient's recall bias for symptom onset time. However, data were collected during patient's admission within a very narrow time after symptom onset. Second, we are not $100 \%$ sure about the accuracy of the diagnosis of STEMI in our study. We did not collect the patient's original ECG file for further independent validation of the diagnoses. Since the CPACS-3 Study had professional project management with both on-line and on-site data monitoring, we believe incorrect diagnosis for STEMI should be minimum. Another limitation is that survivor bias might exist as patients who were dead on arrival or within $10 \mathrm{~min}$ of hospital arrival were excluded. Additionally, we did not collect data on the onset of symptoms and hence could hardly study the possible associations between the onset of symptoms and the prehospital delay to care.

\section{CONCLUSIONS}

In conclusion, the present study demonstrated that patients with STEMI in non-PCI hospitals in China suffered severe time delays to care. Among the four types of delay, prehospital delay should be emphasised although the other three still have room for improvement. Efforts should be made in future to improve prehospital delay among vulnerable populations with low socioeconomic status.

\section{Implication}

Establishment of a prehospital rescue system facilitated with ECG examination and results transmission equipment as well as population-wide health education of seeking medical care in time and chest pain might offer solutions to improve the current clinical practice and enhance the quality of care among patients with STEMI.

\section{Author affiliations}

${ }^{1}$ Clinical Research Institute, Peking University First Hospital, Beijing, China

${ }^{2}$ Peking University Clinical Research Institute, Beijing, China

${ }^{3}$ The George Institute for Global Health at Peking University Health Science Center, Beijing, China

${ }^{4}$ Clinical Epidemiology and EBM Center, Beijing Friendship Hospital, Capital Medical University, National Clinical Research Center for Digestive Disease, Beijing, China

${ }^{5}$ The Department of Cardiology, Capital Medical University Affiliated Beijing Shijitan Hospital, Beijing, China

${ }^{6}$ Fu Wai Hospital, National Center for Cardiovascular Diseases, Beijing, China ${ }^{7}$ Epidemiology and Biostatistics, Peking University School of Public Health, Beijing, China

Acknowledgements The CPACS-3 Study Steering Committee (sorted by the first letter of the family name): Kalipso Chalkidou (National Institute for Health and Clinical Excellence), Runlin Gao* (Cardiovascular Institute and Fuwai Hospital), Dayi Hu (Peking University People's Hospital), Yong Huo (Peking University First Hospital), Yahui Jiao (National Helth and Family Planning Commission of China), Lingzhi Kong (National Health and Family Planning Commission of China), Anushka Patel (The George Institute for Global Health), Eric Peterson (Duke Clinical Research Institute), Fiona Turnbull (The George Institute for Global Health), Mark Woodward (The George Institute for Global Health), Yangfeng Wu* (The George Institute for Global Health at Peking University Health Science Center). *Co-principal investigators.

Contributors LF, ML and YW conceived this study. YW obtained research funding. LF conceived and conducted statistical analyses. WX and XL provided statistical advice and statistical validation. AZ supervised the conduct of the study and data collection. LF, ML, LL, WX, YW and RG interpreted the results. LF drafted the manuscript and all authors contributed substantially to its revision. YW takes responsibility for the paper as a whole.

Funding CPACS-3 Study is an investigator initiated study supported by Sanofi. The George Institute for Global Health at Peking University Health Science Center sponsored the study and owns the data. However, the authors are solely responsible for the design and conduct of this study, all study analyses, the drafting and editing of the manuscript, and its final contents.

Competing interests None declared.

Patient consent for publication Obtained.

Ethics approval The Peking University IRB reviewed and approved the CPACS-3 Trial. The CPACS-3 Study is registered at www.clinicaltrails.gov (NCT01398228).

Provenance and peer review Not commissioned; externally peer reviewed.

Data availability statement Data are available upon reasonable request.

Open access This is an open access article distributed in accordance with the Creative Commons Attribution Non Commercial (CC BY-NC 4.0) license, which permits others to distribute, remix, adapt, build upon this work non-commercially, and license their derivative works on different terms, provided the original work is properly cited, appropriate credit is given, any changes made indicated, and the use is non-commercial. See: http://creativecommons.org/licenses/by-nc/4.0/. 


\section{REFERENCES}

1 Solhpour A, Chang K-W, Arain SA, et al. Ischemic time is a better predictor than door-to-balloon time for mortality and infarct size in ST-elevation myocardial infarction. Catheter Cardiovasc Interv 2016;87:1194-200.

2 Chughtai H, Ratner D, Pozo M, et al. Prehospital delay and its impact on time to treatment in ST-elevation myocardial infarction. Am J Emerg Med 2011;29:396-400.

3 Berger PB, Ellis SG, Holmes DR, et al. Relationship between delay in performing direct coronary angioplasty and early clinical outcome in patients with acute myocardial infarction: results from the global use of strategies to open occluded arteries in acute coronary syndromes (GUSTO-Ilb) trial. Circulation 1999;100:14-20.

4 Foo CY, Bonsu KO, Nallamothu BK, et al. Coronary intervention doorto-balloon time and outcomes in ST-elevation myocardial infarction: a meta-analysis. Heart 2018;104:1362-9.

5 Benamer H, Bataille S, Tafflet M, et al. Longer pre-hospital delays and higher mortality in women with STEMI: the e-MUST registry. Eurolntervention 2016;12:e542-9.

6 George L, Ramamoorthy L, Satheesh S, et al. Prehospital delay and time to reperfusion therapy in ST elevation myocardial infarction. $J$ Emerg Trauma Shock 2017;10:64-9.

7 Duraes AR, Bitar YS, Freitas ACT, et al. Gender differences in STelevation myocardial infarction (STEMI) time delays: experience of a public health service in Salvador-Brazil. Am J Cardiovasc Dis 2017;7:102-7.

8 Post F, Giannitsis E, Riemer T, et al. Pre- and early in-hospital procedures in patients with acute coronary syndromes: first results of the "German chest pain unit registry". Clin Res Cardiol 2012;101:983-91.

9 Shehab A, AlHabib KF, Bhagavathula AS, et al. Clinical presentation, quality of care, risk factors and outcomes in women with acute STelevation myocardial infarction (STEMI): an observational report from six middle Eastern countries. Curr Vasc Pharmacol 2018;16:000-00.

10 Sullivan AL, Beshansky JR, Ruthazer R, et al. Factors associated with longer time to treatment for patients with suspected acute coronary syndromes: a cohort study. Circulation 2014;7:86-94.

11 Peng YG, Feng JJ, Guo LF, et al. Factors associated with prehospital delay in patients with ST-segment elevation acute myocardial infarction in China. Am J Emerg Med 2014;32:349-55.

12 Park YH, Kang GH, Song BG, et al. Factors related to prehospital time delay in acute ST-segment elevation myocardial infarction. $J$ Korean Med Sci 2012;27:864-9.

13 Naegeli B, Radovanovic D, Rickli H, et al. Impact of a nationwide public campaign on delays and outcome in Swiss patients with acute coronary syndrome. Eur J Cardiovasc Prev Rehabil 2011;18:297-304.

14 Quinn T, Johnsen S, Gale CP, et al. Effects of prehospital 12-lead ECG on processes of care and mortality in acute coronary syndrome: a linked cohort study from the myocardial ischaemia national audit project. Heart 2014;100:944-50.

15 Mooney M, McKee G, Fealy G, et al. A review of interventions aimed at reducing pre-hospital delay time in acute coronary syndrome: what has worked and why? Eur J Cardiovasc Nurs 2012;11:445-53.

16 Duan T, Xiang D, Qin W, et al. Impact of establishing regional collaborative network on reperfusion time and prognosis of patients with ST-segment elevated myocardial infarction admitting to community hospitals without percutaneous coronary intervention capacity]. Zhonghua xin xue guan bing za zhi 2014;42:641-5.

17 Wu Y, Li S, Patel A, et al. Effect of a quality of care improvement initiative in patients with acute coronary syndrome in resourceconstrained hospitals in China. JAMA Cardiol 2019;4.

18 Cannon CP, Brindis RG, Chaitman BR, et al. 2013 ACCF/AHA key data elements and definitions for measuring the clinical management and outcomes of patients with acute coronary syndromes and coronary artery disease: a report of the American College of cardiology Foundation/American heart association Task force on clinical data standards (writing Committee to develop acute coronary syndromes and coronary artery disease clinical data standards). Circulation 2013;127:1052-89.

19 Ladwig KH, Fang X, Wolf K, et al. Comparison of delay times between symptom onset of an acute ST-elevation myocardial infarction and hospital arrival in men and women /=65 years of age.: findings from the multicenter Munich examination of delay in patients experiencing acute myocardial infarction (Medea) study. Am J Cardiol 2017:120:2128-34

20 Wah W, Pek PP, Ho AFW, et al. Symptom-to-door delay among patients with ST-segment elevation myocardial infarction in Singapore. Emerg Med Australas 2017;29:24-32.

21 Ibanez B, James S, Agewall S, et al. Esc guidelines for the management of acute myocardial infarction in patients presenting with ST-segment elevation: the task force for the management of acute myocardial infarction in patients presenting with ST-segment elevation of the European Society of cardiology (ESC). Eur Heart $J$ 2017;2017:1-66.

22 O'Gara PT, Kushner FG, Ascheim DD, et al. 2013 ACCF/AHA guideline for the management of ST-elevation myocardial infarction: a report of the American College of cardiology Foundation/American heart association Task force on practice guidelines. Circulation 2013;127:e362-425.

23 Steg PG, James SK, Atar D, et al. Esc guidelines for the management of acute myocardial infarction in patients presenting with ST-segment elevation. Eur Heart J 2012;33:2569-619.

24 Hussey MA, Hughes JP. Design and analysis of stepped wedge cluster randomized trials. Contemp Clin Trials 2007;28:182-91.

25 Fujii T, Masuda N, Suzuki T, et al. Impact of transport pathways on the time from symptom onset of ST-segment elevation myocardial infarction to door of coronary intervention facility. $J$ Cardiol 2014;64:11-18.

26 Isezuo S, Subban V, Krishnamoorthy J, et al. Characteristics, treatment and one-year outcomes of patients with acute coronary syndrome in a tertiary hospital in India. Indian Heart $J$ 2014;66:156-63.

27 Noguchi M, Ako J, Morimoto T, et al. Modifiable factors associated with prolonged door to balloon time in patients with ST-segment elevation myocardial infarction undergoing primary percutaneous coronary intervention. Heart Vessels 2018;33:1139-48.

28 Sederholm Lawesson S, Isaksson R-M, Ericsson M, et al. Gender disparities in first medical contact and delay in ST-elevation myocardial infarction: a prospective multicentre Swedish survey study. BMJ Open 2018;8:e020211.

29 Zhang B, Zhang W, Huang R, et al. Gender and age differences associated with prehospital delay in Chinese patients presenting with ST-elevation myocardial infarction. J Cardiovasc Nurs 2016;31:142-50.

30 Allana S, Moser DDK, Ali DTS, et al. Sex differences in symptoms experienced, knowledge about symptoms, symptom Attribution, and perceived urgency for treatment seeking among acute coronary syndrome patients in Karachi Pakistan. Heart \& Lung 2018;47:584-90.

31 Sederholm Lawesson S, Isaksson R-M, Thylén I, et al. Gender differences in symptom presentation of ST-elevation myocardial infarction - An observational multicenter survey study. Int J Cardiol 2018;264:7-11

32 Allana S, Khowaja K, Ali TS, et al. Gender differences in factors associated with prehospital delay among acute coronary syndrome patients in Pakistan. J Transcult Nurs 2015;26:480-90.

33 Moser DK, McKinley S, Dracup K, et al. Gender differences in reasons patients delay in seeking treatment for acute myocardial infarction symptoms. Patient Educ Couns 2005;56:45-54.

34 Diercks DB, Peacock WF, Hiestand BC, et al. Frequency and Consequences of Recording an Electrocardiogram $>10$ Minutes After Arrival in an Emergency Room in Non-ST-Segment Elevation Acute Coronary Syndromes (from the CRUSADE Initiative). Am J Cardiol 2006;97:437-42

35 Armstrong PW, Gershlick AH, Goldstein P, et al. Fibrinolysis or primary $\mathrm{PCl}$ in ST-segment elevation myocardial infarction. $N$ Engl J Med 2013;368:1379-87.

$36 \mathrm{Li} \mathrm{J,} \mathrm{Li} \mathrm{X,} \mathrm{Ross} \mathrm{JS,} \mathrm{et} \mathrm{al.} \mathrm{Fibrinolytic} \mathrm{therapy} \mathrm{in} \mathrm{hospitals} \mathrm{without}$ percutaneous coronary intervention capabilities in China from 2001 to 2011: China PEACE-retrospective AMI study. Eur Heart J 2017;6:232-43. 